Proceedings

\title{
Biodegradable Coating on Packaging Paper Made from Fibres of Invasive Plant Spieces Fallopia japonica $^{+}$
}

\author{
Gregor Lavrič ${ }^{1}$ and Urška Vrabič Brodnjak ${ }^{2}$ \\ 1 Pulp and Paper Insitute Ljubljana, Bogišićeva 8, SI-1000 Ljubljana, Slovenia; gregor.lavric@icp-lj.si \\ 2 Department of Textiles, Graphic Arts and Design, Faculty of Natural Sciences and Engineering, University \\ of Ljubljana, Snežniška 5, SI-1000 Ljubljana, Slovenia \\ * Correspondence: urska.vrabic@ntf.uni-lj.si; Tel.: +386-1-200-32-82 \\ + Presented at the First International Conference on "Green" Polymer Materials 2020, 5-25 November 2020; \\ Available online: https://cgpm2020.sciforum.net/.
}

Published: 3 November 2020

\begin{abstract}
In this study, a biodegradable chitosan coating was applied to paper made from invasive alien plant species Fallopia japonica. The aim of the study was to investigate the influence of different concentrations of chitosan in the coating solution (5 wt\% and $10 \mathrm{wt} \%)$ on the physical and mechanical properties of the paper substrate. Scanning electron microscopy was used to evaluate the influence of the coating on the microstructures and porosity of the paper. The results showed the compatibility of chitosan and paper substrate. The water and moisture resistance of coated paper substrates decreased. The tensile properties of the coated paper showed promising results at lower concentrations (5\%) of chitosan. Tensile strength and elongation at break increased, mainly due to the combination of chitosan matrix and polymer chain interactions. Thermogravimetric analysis revealed thermal stability and weight changes in coated paper. A high weight loss of $20 \%$, between $300{ }^{\circ} \mathrm{C}$ and $400{ }^{\circ} \mathrm{C}$, was found for $5 \%$ to $10 \%$ chitosan-coated paper due to the degradation of the chitosan main chains. The coated papers had better thermal, mechanical and water resistant properties. Considering the bio-based nature of the coating and the paper substrate used, the process can offer an environmentally friendly and sustainable solution.
\end{abstract}

Keywords: biopolymers; chitosan; properties; materials

\section{Introduction}

Fallopia japonica is a plant, native to East Asia, Japan, China and Korea, but in North America and Europe it is classified as invasive species. The root system and strong growth of these plants can damage buildings, streets, paving, retaining walls etc. It forms thick colonies, which crowd out other herbaceous species [1]. In our project it was found out that the stem biomass of Fallopia japonica contains 40 percent of cellulose, which is comparable to the raw materials from which paper fibers are typically produced. With chemical and mechanical procedures and treatments, the fibers from Fallopia japonica were prepared and successfully the packaging paper has been produced.

Generally, paper is widely used in packaging applications and it is considered as environmentally friendly substrate. It consists of a porous cellulose structure, composed of longchain molecules in a crystalline state with amorphous regions in-between. Due to hydrophilic nature of cellulose and fiber network porosity, water barrier properties are limited. Conventional coatings that are used to improve water resistance, involve synthetic polymers such as polyethylene, rubber latex, polyvinyl alcohol etc. Natural renewable polymers have been the focus of many researches in recent years. Paper coatings are also commonly used with wax, but the recyclability of laminated and 
waxed papers is limited due to the separation from the paper, which is connected to the environmental issues [2,3].

Polysaccharides have become widely used as coating solutions, including chitin, chitosan, alginates etc. The availability on the market and great properties such as non-toxicity, gas, aroma and grease barriers make it possible to use these materials in many applications [4]. On the other hand, polysaccharides have low hydrophilicity and limited use in materials where water vapour barriers are of utmost importance [5,6].

Chitosan, a non-toxic and widely used polysaccharide, is obtained by deacetylation of chitin [5]. Due to its properties such as high crystallinity and hydrogen bonding between molecular chains with high oxygen properties, it has aroused interest in food packaging as edible films and coatings [5-9]. One of the advantages of chitosan is its high grease barrier properties, which are due to its positive charge at the amino group under acidic conditions, as it binds negatively charged molecules [5]. Its good barrier properties (antimicrobial, mechanical, against grease, oxygen) chitosan coatings can also be used as a barrier in packaging [8-11]. In several chitosan coatings, additional biopolymers have been added to achieve hydrophobic properties of the substrate [11-14]. In this study biodegradable coating such as polysaccharide chitosan, was applied to paper made from Fallopia japonica. Namely, non coated paper from Fallopia japonica has high hydrophilic character and therefore it is not suitable for all packaging products. The aim of the research was to investigate the influence of different concentrations of chitosan in coating solution $(5 \%$ and $10 \% w / w)$ on the physical and mechanical properties of the mentioned paper substrate. Considering the biobased nature of the coating and used paper substrate, the procedure can offer environmentally friendly and sustainable solution toward new packaging material. Using a Fallopia japonica as a source for the paper fibers, the need for the wood fibers could decrease and at the same time, the negative impact on the environment could reduce.

\section{Experiments}

\subsection{Materials}

Chitosan, with the molecular weight $20 \mathrm{kDa}$ and deacetylation degree higher than $85 \%$, was purchased from Sigma Aldrich (Austria). Acetic acid (98\%) and glycerol were obtained from Sigma Aldrich (Austria). In the research, uncoated paper made from Fallopia japonica, with grammage $100 \mathrm{~g} / \mathrm{m}^{2}$ was used. Paper was produced on a paper maschine (Andritz AG, Graz, Austria) located in Pulp and Paper Institute in Ljubljana, Slovenia.

\subsection{Preparation of Coating Solutions and Coating Procedure}

First, the solutions were prepared separately and the coating was carried out. Two different chitosan solutions were prepared by dissolving $5 \mathrm{~g}$ or $10 \mathrm{~g}$ of chitosan in $100 \mathrm{~mL}$ of $2 \%$ acetic acid and then adding $5 \mathrm{~mL}$ of glycerol. The solution was then mixed for $10 \mathrm{~min}$ at a stirring speed of $800 \mathrm{rpm}$ (at $85^{\circ} \mathrm{C}$ ) and cooled to room temperature. The solution was filtered through a polyester screen (mesh size 140 , mesh opening $160 \mu \mathrm{m})$, as the solution contained small lumps.

After the solutions were prepared, the coatings were applied with a coater (K-Coater K101). The samples were coated on a coating table at ambient temperature with a $120 \mu \mathrm{m}$ wire rod bar. The coated samples were then dried (at $80{ }^{\circ} \mathrm{C}$ for $10 \mathrm{~min}$ ). A solution of $5 \mathrm{~g} / \mathrm{m}^{2}$ was applied to each paper.

Paper sheets were coated using two coating solutions of chitosan:

(1) Uncoated paper-U

(2) Coated with chitosan (5\%) - C5

(3) Coated with chitosan $(10 \%)-\mathrm{C} 10$

\subsection{Characterisation of the Samples}

2.3.1. Grammage, Thickness and Density 
To determine the amount of coating on the paper, the basis weight (grammage) was determined according to standard ISO 536. The standards define the analysis of 10 samples, which should be cut to size $10 \times 10 \mathrm{~cm}$ and weighed.

The thickness of the samples was determined with a digital micrometre Mitutoyo Corporation, Kanagawa, Japan, to an accuracy of $0.0001 \mu \mathrm{m}$. The measurements of the samples were performed at 10 random locations on each sample. Density was calculated according to standard ISO 534.

\subsubsection{Moisture Content, Absorptiveness (Cobb Value) and Water Vapour Permeability (WVP)}

The moisture content was determined at ISO 287. The weight loss after drying in a laboratory oven at $105 \pm 1{ }^{\circ} \mathrm{C}$ until the weight of each paper sample ( 5 replicates) was measured. Absorptiveness was determined in accordance with standard ISO 535. A given amount of water was in contact with the paper for $60 \mathrm{~s}$ (10 samples) and the weight differences were compared. The water vapour permeability (WVP) was determined as described in standard ISO 2528. The test cups were filled with water and a single sample was placed between the cup and the ring lid of each cup. The samples (three paralles) with the exposed area of $50 \mathrm{~cm}^{2}$ were tested at $90 \pm 2 \% \mathrm{RH}$ and $38 \pm 2{ }^{\circ} \mathrm{C}$ for $24 \mathrm{~h}$.

\subsubsection{Tensile Properties}

Tensile strength (TS) and elongation at break (E) of papers were analysed in the standard atmosphere at $23{ }^{\circ} \mathrm{C}$ of temperature and $50 \%$ of relative humidity on a tensile testing machine Instron (Norwood, MA, USA) 6022. The cross speed head was $0.15 \mathrm{~mm} / \mathrm{s}$ and paper stripes of $18 \mathrm{~cm}$ in length and $1.5 \mathrm{~cm}$ in width (in machine-MD and cross-CD direction) were used.

\subsubsection{Thermogravimetric Analysis (TGA)}

Thermogravimetric analysis (TGA) test was carried out with thermogravimmetric analyser (Mettler Toledo, USA). All analysed samples with weight around $10 \mathrm{mg}$ were heated under dynamic mode, in $\mathrm{N}_{2}$ atmosphere, at flow rate of $40 \mathrm{~mL} / \mathrm{min}$ from 30 to $600^{\circ} \mathrm{C}$. The heating rate was $10^{\circ} \mathrm{C} / \mathrm{min}$ (low rate $50 \mathrm{~mL} \mathrm{~min}^{-1}$ ) in order to prevent any thermoxidative degradation.

\subsubsection{Surface Properties - Scanning Electron Microscope (SEM)}

Surface properties were analysed with a scanning electron microscope (JSM-6060 LV). The instrument operated at $10 \mathrm{kV}$ and at the magnification $500 \times$.

\subsubsection{Statistics}

Results for grammage, thickness, density and specific surface volume are presented as mean \pm standard deviation.

\section{Results and Discussion}

\subsection{Basic Properties}

To determine the properties and influence of coatings on paper, basic properties should first be evaluated. The grammage, thickness and density of the analysed samples are shown in Table 1. Grammage and thickness have an influence on the tensile properties of the paper. The results show that 5 and $10 \mathrm{~g} / \mathrm{m}^{2}$ coating were successfully applied to the samples.

Table 1. Grammage, thickness, density of uncoated and coated samples with standard deviation.

\begin{tabular}{cccc}
\hline Sample & $\begin{array}{c}\text { Grammage } \\
{\left[\mathbf{g} / \mathbf{m}^{2}\right]}\end{array}$ & $\begin{array}{c}\text { Thickness } \\
{[\mathbf{m m}]}\end{array}$ & $\begin{array}{c}\text { Density } \\
{\left[\mathbf{k g} / \mathbf{m}^{3}\right]}\end{array}$ \\
\hline $\mathrm{U}$ & $98 \pm 1.5$ & $0.17 \pm 0.002$ & $620 \pm 2$ \\
$\mathrm{C} 5$ & $105 \pm 0.5$ & $0.22 \pm 0.001$ & $645 \pm 3$ \\
$\mathrm{C} 10$ & $110 \pm 0.3$ & $0.23 \pm 0.001$ & $648 \pm 1$ \\
\hline
\end{tabular}




\subsubsection{Moisture Content, Absorptiveness (Cobb Value) and Water Vapour Permeability (WVP)}

To analyse the hydrophilic/hydrophobic properties of paper coatings, moisture, water absorptiveness and water vapour permeability were determined (Figure 1). Uncoated paper is hydrophilic and, due to its porous structure, has a higher water and moisture absorption capacity $(9.26 \%)$ than coated paper. As expected, the worst water barrier properties were found for uncoated paper. As already described, fibres of Fallopia japonica are hydrophobic. For coated paper, the best moisture, Cobb and WVP values were found in a sample containing 10\% chitosan. In general, glycerol as added plasticizer increases the hydrophilicity of the substrate. In our study, the small amount of glycerol was added to increase the flexibility of the coating. During the coating process, the surface and porous structure of uncoated paper was filled with chitosan, which resulted in increased surface hydrophobicity.

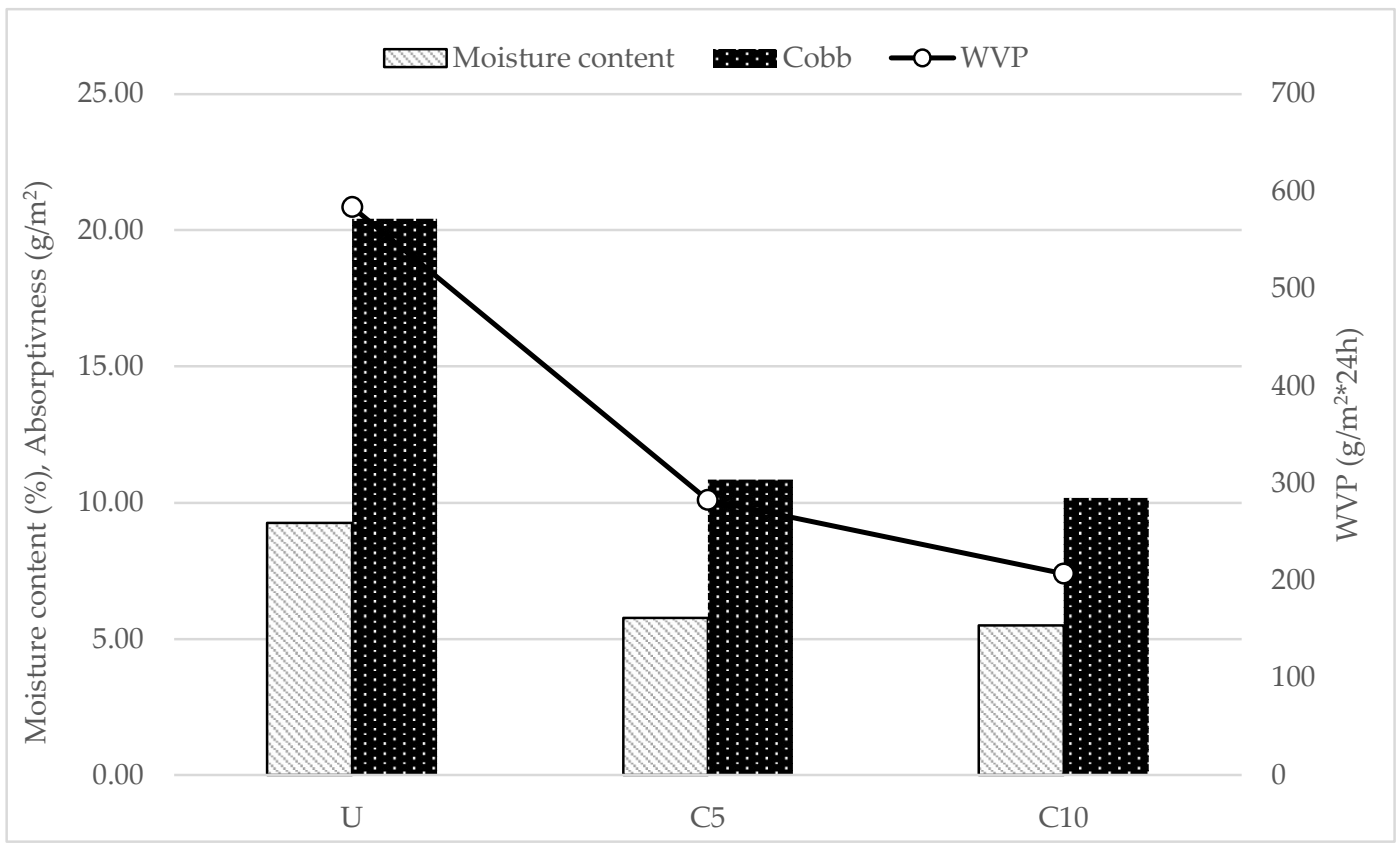

Figure 1. Moisture contenct, absorptiveness and water vapour permeability of uncoated, $5 \%$ chitosan (C5) and $10 \%$ chitosan (C10) coated paper.

\subsubsection{Tensile Properties and Thermogravimetric Analysis}

Different strength properties are required to ensure good runnability of the paper web throughout the papermaking process. Since the base paper is wetted in the coating process, good strength is required. The tensile-elongation behavior depends on the moisture content of the paper. Namely, tensile strength increases, but tear and elongation are reduced when the paper is dried. Polysaccharides blends with other polymers, in varying proportions, to also improve the mechanical properties. Namely, the mechanical behavior of packaging films is a very important property of the film to maintain its authenticity and to resist the environmental influences during the packaging application. The addition of chitosan increased both tensile strength and elongation (Table 2). As expected, the highest strength in the coated sample was 10\% chitosan (40 MPa in MD and $64 \mathrm{MPa}$ in $\mathrm{CD}$ ). The same trend was observed for elongation at break. The lowest values were for uncoated paper and the highest again for $10 \%$ chitosan-coated paper. 
Table 2. Tensile strength (TS) and elongation (E) of uncoated (U), $5 \%$ chitosan (C5) and 10\% chitosan (C10) coated paper in cross maschine direction (CD) and machine direction (MD).

\begin{tabular}{ccccc}
\hline \multirow{2}{*}{ Sample } & \multicolumn{2}{c}{ TS [MPa] } & \multicolumn{2}{c}{ E (\%) } \\
\cline { 2 - 5 } & MD & CD & MD & CD \\
\hline U & 25 & 58 & 3.7 & 2.0 \\
C5 & 36 & 59 & 4.9 & 3.6 \\
C10 & 40 & 64 & 5.1 & 4.2 \\
\hline
\end{tabular}

The results of the thermogravimetric analysis are shown in Figure 2. The initial weight loss in uncoated paper was observed between $250^{\circ} \mathrm{C}$ and $350{ }^{\circ} \mathrm{C}$. Furthermore, the total weight loss could be divided into three stages. First stage in the range $0^{\circ} \mathrm{C}$ to $100{ }^{\circ} \mathrm{C}$, which could be attributed to the loss of water from the surface. The second was observed between $300{ }^{\circ} \mathrm{C}$ and $350{ }^{\circ} \mathrm{C}$. Finally the third weight loss in the range between $350{ }^{\circ} \mathrm{C}$ and $400{ }^{\circ} \mathrm{C}$. The third weight loss was in chitosan samples due to degradation of the polymer chain, which could be due to the removal of the acetic acid used in the chitosan solutions. The results confirmed that the samples with added chitosan had an increased thermal stability compared to an uncoated sample.

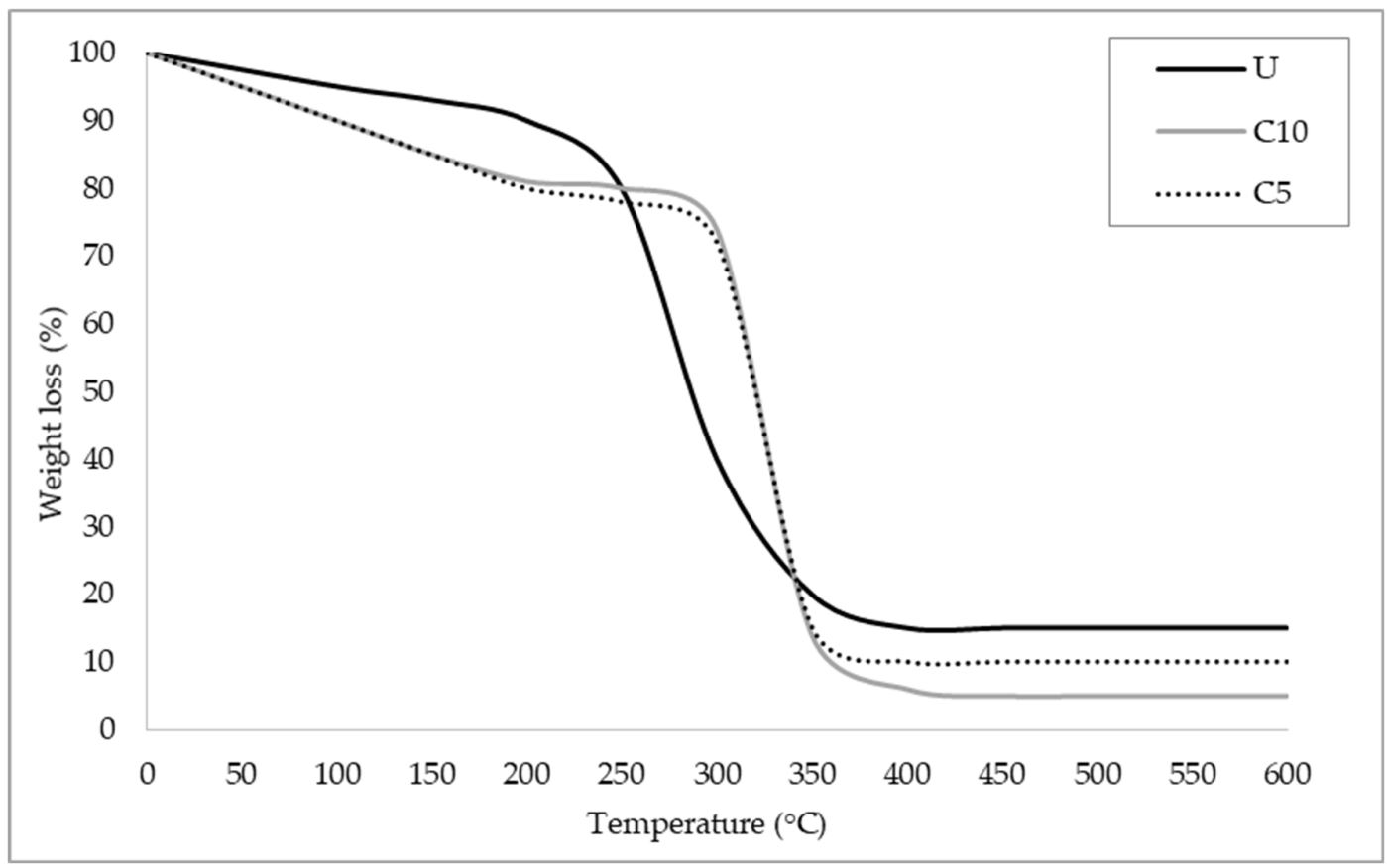

Figure 2. TGA curves of uncoated, $5 \%$ chitosan (C5) and $10 \%$ chitosan (C10) coated paper.

\subsubsection{Surface Properties}

The surface properties of coated papers are consistent with changes in both mechanical and water barrier properties. The absorption, thickness and moisture of uncoated paper have a major influence on the properties of coatings. Good fibre coverage results in good smoothness of the coated paper. If the coating weight is unevenly distributed, many properties can deteriorate after coating, which can affect the printing process. The figures also show that, compared to uncoated paper, the chitosan content fills the surface and closes the pores (Figure 3). These results are consistent with the changes in mechanical and water barrier properties in coated samples. 


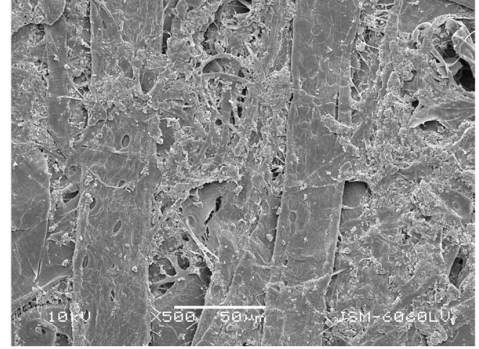

$\mathbf{U}$

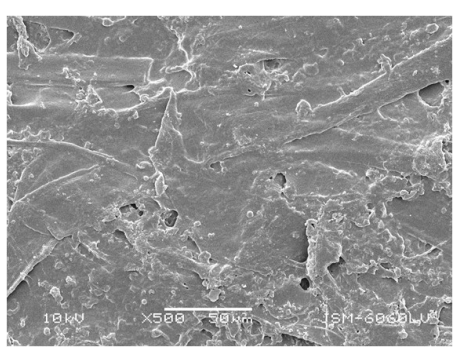

C5

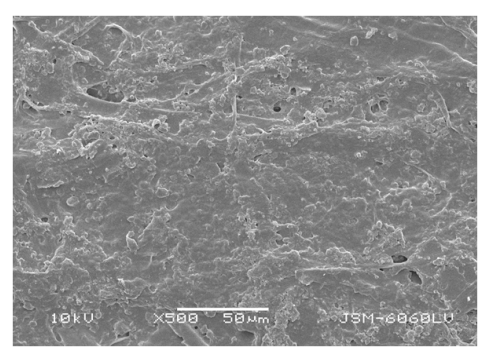

C10

Figure 3. SEM micrographs of uncoated, $5 \%$ chitosan (C5) and $10 \%$ chitosan (C10) coated paper at $500 \times$ magnification.

\section{Conclusions}

Characteristic features of the plant Fallopia japonica showed that it can be used as part of paper production, including coated paper. A detailed study of two different amounts of the chitosan solution was carried out. Our research has confirmed that the bio-based chitosan coating has been successfully applied to paper and many properties have been improved. These include water barrier, tensile and thermal properties. The results have shown that $5 \%$ chitosan is sufficient for a suitable paper coating. This leads to a promising solution for the application in the packaging sector. On the other hand the solution for invasive plant spieces could be a good solution for the environmental impact in Europe. In the future, the properties of different bio-based coatings on Fallopia japonica paper will be investigated.

Author Contributions: G.L. and U.V.B. conceived and designed the experiments; G.L. performed the experiments; G.L. and U.V.B. analyzed the data; G.L. and U.V.B. wrote the paper. All authors have read and agreed to the published version of the manuscript.

Acknowledgments: This research was part of the project "Applause-Alien Plant Spieces, from harmful to useful with citizens", which was co-funded by the EU Regional Development Fund. No funds were received for covering the costs to publish in open access.

Conflicts of Interest: The authors declare no conflict of interest.

\section{Abbreviations}

The following abbreviations are used in this manuscript:

CD Cross machine direction

E Elongation

MD Machine direction

TGA Thermogravimetric analysis

TS Tensile strength

WVP water vapour permeability

\section{References}

1. Kurose, D.; Renals, T.; Shaw, R.; Furuya, N.; Takagi, M.; Evans, H. Fallopia japonica, an increasingly intractable weed problem in the UK: Can fungi help cut through this Gordian knot? Mycologist 2006, 20, $126-129$.

2. Saji, V.S. Wax-based Artificial Superhydrophobic Surfaces and Coatings. Colloid Surface A 2020, 602, 125132.

3. Wang, W.; Wang, Y.; Liu, Z.; Han, Y.; Wang, C. Study on application performance of oxidized polyethylene wax in powder coatings. Prog. Org. Coat. 2019, 136, 105294.

4. Vrabič Brodnjak, U. Influence of ultrasonic treatment on properties of bio-based coated paper. Prog. Org. Coat. 2017, 103, 93-100. 
5. Bordenave, N.; Grelier, S.; Coma, V. Hydrophobization and antimicrobial activity of chitosan and paperbased packaging material. Biomacromolecules 2010, 11, 88-96.

6. Bordenave, N.; Grelier, S.; Pichavant, F.; Coma, V. Water and moisture susceptibility of chitosan and paperbased materials: Structure-property relationships. J. Agr. Food Chem. 2007, 55, 9479-9488.

7. Xu, Y.X.; Kim, K.M.; Hanna, M.A.; Nag, D. Chitosan-starch composite film: preparation and characterization. Ind. Crop. Prod. 2005, 21, 185-192.

8. Wang, S.; Jing, Y. Effects of a chitosan coating layer on the surface properties and barrier properties of kraft paper. BioResources 2016, 11, 1868-1881.

9. Ham-Pichavant, F.; Sèbe, G.; Pardon, P.; Coma, V. Fat resistance properties of chitosan-based paper packaging for food applications. Carbohyd. Polym. 2005, 61, 259-265.

10. Rastogi, V.K.; Samyn, P. Bio-based coatings for paper applications. Coatings 2015, 5, 887-930.

11. Reis, A.B.; Yoshida, C.M.; Reis, A.P.C.; Franco, T.T. Application of chitosan emulsion as a coating on Kraft paper. Polym. Int. 2011, 60, 963-969.

12. Mujtaba, M.; Morsi, R.E.; Kerch, G.; Elsabee, M.Z.; Kaya, M.; Labidi, J.; Khawar, K.M. Current advancements in chitosan-based film production for food technology; A review. Int. J. Biol. Macromol. 2019, 121, 889-904.

13. Cherpinski, A.; Torres-Giner, S.; Cabedo, L.; Méndez, J.A.; Lagaron, J.M. Multilayer structures based on annealed electrospun biopolymer coatings of interest in water and aroma barrier fiber-based food packaging applications. J. Appl. Polym. Sci. 2018, 135, 45501.

14. Kopacic, S.; Walzl, A.; Zankel, A.; Leitner, E.; Bauer, W. Alginate and chitosan as a functional barrier for paper-based packaging materials. Coatings 2018, 8, 235.

Publisher's Note: MDPI stays neutral with regard to jurisdictional claims in published maps and institutional affiliations.

(C) 2020 by the authors. Submitted for possible open access publication under the terms and conditions of the Creative Commons Attribution (CC BY) license (http://creativecommons.org/licenses/by/4.0/). 